\title{
Economic security and innovation activity of personnel - determinants of sustainable development of enterprises
}

\author{
Maryna Adamenko ${ }^{1, *}$, Ievgeniia Mishchuk $^{2}$, and Olena Zinchenko ${ }^{1}$ \\ ${ }^{1}$ Kryvyi Rih National University, Department of Finance of Business Entities and Innovative Development, Kryvyi Rih, Ukraine \\ ${ }^{2}$ Kryvyi Rih National University, Department of Accounting, Taxation, Public Management and Administration, Kryvyi Rih, Ukraine
}

\begin{abstract}
The article substantiates that achievement of certain economic security level set by management for the current time point is a necessary but insufficient condition of further development of the enterprise. When the mentioned condition is fulfilled, the degree of its personnel's innovation activity should also be considered. The article presents further development of the methods of assessing the level of the dependent part of economic security of the enterprise's stakeholders, including the personnel, which, unlike others available, is based on estimation of outstanding expenditures. Innovation activity of the personnel is determined to depend on their attitudes to innovations. The article presents a developed economic and statistic toolkit of assessing the personnel's probable attitudes to implementation of innovations considering the degree of recognizing the necessity of innovations and awareness of the enterprise's activities in terms of innovations. The level of probable (expected) attitudes to innovations is taken as a basis for a combined classification of particular personnel categories. The article suggests a matrix approach to determining the type of enterprise development based on comparison of the level of economic security for the current time point and the personnel's innovation activity.
\end{abstract}

\section{Introduction}

\subsection{Problem statement and its topicality substantiation}

During its functioning, any enterprise goes through several stages of development. However, even on achieving the best results in its economic activities, it cannot always maintain this state. This is, first of all, caused by the volatile nature of the external environment. The competitive environment stimulates activities of the enterprise which aim at further functioning and which are of interest for owners. Sustainable development is based on certain factors, its economic security and innovation activity of its personnel being the most significant among them under current economic conditions. In case of danger, key tasks of the enterprise shift towards survival and stabilization of its performance. Due to that, sustainable development plays a smaller part. Yet, for further development, the enterprise should leave its comfort zone - the zone of its economic security. However, in any case, possibility of development is provided at the expense of innovation activities of its personnel. At the same time, economic processes in Ukraine do not allow national enterprises to ensure transition to intensive performance forms. One of the reasons for this is poor efficiency of innovation activities, insufficient involvement of personnel into innovative processes.

Foreign practices of innovation management enable asserting that qualitative use of personnel's innovation potential and formation of their high innovation activity are crucial factors of increasing innovation activity efficiency at any enterprise under conditions of current economic development. Thus, one can assert that it is the level and dynamism of personnel's innovation development, the degree of use of their innovation potential under current economic conditions that ensure sustainable economic development and competitiveness of enterprises.

No doubt, implementation of innovations is very important but personnel's attitude to them may be different - from active recognition, approval and desire to implement to active aversion and resistance to implementation. The latter may be caused by many factors, poor awareness of necessity, reasons and peculiarities of the enterprise innovation activity being one of them. Considering the above mentioned, the issue of enhancement of methodological approaches to assessing probable attitudes of personnel to innovation implementation, development of corresponding economic and statistic tools is gaining topicality.

Thus, assessment of qualitative use of personnel's innovation potential and economic security as modern determinants of sustainable development of an enterprise require enhancement.

\footnotetext{
* Corresponding author: adamenko@ua.fm
} 


\subsection{Analysis of the latest researches and publications}

In current literature, many scientific works deal with assessment and management of innovation potential of an enterprise. Issues of this type of assessment are considered in number of works, however, considering assessment of enterprise innovation potential as a whole, scholars do not pay sufficient attention to assessment of innovation potential and activity of enterprise personnel. In particular, the authors of $[1,2]$ present indicators of assessment of personnel's innovation potential at an enterprise, while the works [3-8] consider some of the relevant methods.

Quality characteristics of employees' innovation potential and their attitudes to innovations are dealt with in [9-12]. Importance of this kind of assessment is stated but corresponding analytical tools are not indicated.

Availability and conditions of the innovation potential of enterprises' and organizations' personnel impact the Global Innovation Index which dropped from the 43rd place in 2018 to the $47^{\text {th }}$ place in 2019 [13-15]. An entire section is devoted to human capital as a component of the above index. The main indicators in the section are the following: education is on the $43^{\text {rd }}$ place in the world, higher education and research and developments take the $37^{\text {th }}$ and $54^{\text {th }}$ places respectively (2019) [15].

Review of recent researches and publications demonstrate that personnel's innovation potential use is not sufficiently covered, and economic and statistic assessment of probable personnel's attitudes to innovation implementation is not almost considered.

We believe that all existing indicators and methods of assessing personnel's innovation potential including those describing personnel's attitudes to innovations, their innovation activity have the right to exist. In the innovation theory there are no strict requirements, criteria or rules demanding application of certain techniques of assessing innovation activity of an enterprise or its innovation potential and, therefore, managers select approaches to this assessment considering various conditions of enterprise performance.

According to the scholars dealing with assessment of personnel's innovation potential and national practitioners, the methods of point assessment, expert assessment, the index method, the method of relatives considering levels of significance, correlation analysis, methods of qualimetric assessment and others are the most widely used. Variety of methods of analyzing enterprise personnel's innovation potential is caused by complexity of consideration and quantitative assessment of factors impacting the level of personnel's innovation potential. Besides, application of the methods of expert and point assessment introduce certain subjectivity into the analysis. Due to this, we find it reasonable to apply a mixed approach to assessment of personnel's innovation potential at the enterprise combining qualitative and quantitative indicators and tools. Thus, in our opinion, when assessing personnel's attitudes to innovations, the degree of their awareness of innovative processes at the enterprise, it is reasonable to apply point assessment. Economic and mathematical analysis is relevant for quantitative characteristic of the degree of their behavior inertia when implementing innovations.

Besides, there are many various approaches to assessment of the economic security level. From our point of view, the most appropriate ones in practical terms are those based on determining values of deficit of net and operating income as well as the short-received EBITDA value [16, p.12-14]. The authors of [17, p.23-25] consider the functional dimension of modern threats to sustainable development. Methods suggested in those works enable assessment of the level of enterprise economic security but they do not consider the level of security of stakeholders, enterprise personnel being among them.

\section{Results}

As a complement to the modern idea of enterprise performance, we find it reasonable to compare it with an operating complex mechanism driven by the engine but only if there is enough fuel for its performance. It is obvious that the performance duration, the covered distance and/or the number of movements depend on the amount of fuel. Such analogy enables better understanding of modern determinants of sustainable development of any enterprise. Personnel's innovation activity is one of the determinants. This very engine enables the enterprise to move, i.e. develop in the required direction. But a mechanism needs fuel to function. We believe that enterprise economic security is the fuel as it is the foundation underlying the kind of activities that aims at sustainable development. Moreover, certain types of fuel ensure greater engine power. Within the framework of the present research, this means that personnel of an economically secure enterprise focus more efforts on innovation activity aimed at sustainable development of the enterprise. Commonly, part of this activity is devoted to overcoming the unsecure state.

Personnel's innovation potential is treated as a component of that of the enterprise and means the ability of personnel to use the totality of their own innovation capabilities of active production, comprehension and implementation of innovations in their activities and the enterprise performance in order to reach the set goals and receive positive effects.

The level of using personnel's innovation potential depends directly on the degree of their recognizing the necessity of innovations and their awareness of planned innovative processes at the enterprise as this is what influences efficiency of new developments in future.

Degrees of personnel's recognition of the necessity of innovations and awareness of their development and implementation at the enterprise should be assessed through quick tests and statistic observations during surveys. The main task of such assessment is to determine the personnel's opinion on whether innovations are an important and preferential direction of the enterprise development, and whether they are aware of measures for development, implementation and use of innovations at the enterprise.

Answers to these questions enable working out the integral coefficient of personnel's probable (expected) 
attitudes to implementation of innovations:

$$
K_{S}=K_{V} K_{O},
$$

where $K_{V}$ is the coefficient describing the degree of recognizing the necessity of innovations by personnel;

$K_{O}$ is the coefficient describing the degree of personnel's awareness of planned innovative processes at the enterprise.

In terms of mathematics, we suggest determining the coefficients $K_{V}$ and $K_{O}$ as average values of the results of interviewing the personnel and by the 10-point scale according to the criteria matrix (Table 1).

Table 1. The matrix of the criteria of probable (expected) attitudes of enterprise personnel to innovation implementation.

\begin{tabular}{|c|c|c|}
\hline $\begin{array}{r}\text { Degree of } \\
\text { awareness } \\
\left(K_{O}\right)\end{array}$ & Aware & Unaware \\
$\begin{array}{l}\text { Degree of } \\
\text { necessity } \\
\text { recognition }\left(K_{V}\right)\end{array}$ & & \\
\hline Recognize & Obvious activity & Potential activity \\
& $6 \leq K_{V} \leq 10 ;$ & $6 \leq K_{V} \leq 10 ;$ \\
& $6 \leq K_{O} \leq 10$ & $1 \leq K_{O} \leq 5$ \\
\hline & Obvious inactivity & Potential inactivity \\
Do not recognize & $1 \leq K_{V} \leq 5 ;$ & $1 \leq K_{V} \leq 5 ;$ \\
& $6 \leq K_{O} \leq 10$ & $1 \leq K_{O} \leq 5$ \\
\hline
\end{tabular}

So, the value of the obtained integral coefficient may vary from 1 to 100 .

Considering the criteria of assessment of the coefficients $K_{V}$ and $K_{O}$ given in Table 1 , the scale of criterion assessment of the integral coefficient of probable (expected) attitudes of personnel to innovation implementation is determined. The scale can be presented in the following way:

$1-25$ points is a low level of $K_{S}$. Personnel is potentially expected to be inactive in innovation implementation. Besides, this criterion mediately describes inactivity of owners and managers of the enterprise, or testifies to the incorrectly developed innovation strategy (personnel is unaware of innovation implementation). To increase the level of $K_{S}$, the enterprise management should:

1) revise or develop a new innovation strategy to increase personnel's activity and motivation in implementing innovations. The strategy should be consistent, understandable for realizers and have clear results (to recognize innovations, personnel should understand: what to do, in which succession, expected results, expected benefits (additional income));

2) develop a complex of measures for training, psychological training, development of personnel's creativity in the field of innovation activities;

3) develop a system of stimulating personnel's innovation activities.

26-50 points is an average level of $K_{S}$. Personnel activity is expected to be insufficient as they are unaware (badly aware) of innovation implementation or do not recognize (recognize insufficiently) the innovation necessity for the enterprise. At this stage, to increase the level of $K_{I}$ the following should be done:
1) to ensure personnel's awareness of innovation implementation through revision and enhancement of the innovation strategy, policy and current innovation plans in terms of their purposefulness as regards final results, openness and understandability;

2) to carry out necessary psychological training, explanatory work concerning the necessity of innovation implementation and enhance quality of teaching innovation activities to personnel in order to increase the degree of innovation recognition;

3) to enhance the current system of stimulating personnel's innovation activities.

51-100 points is a high level of $K_{S}$. Employees are expected to implement innovations actively. Enterprise management should apply an effective system of incentives to incentivize employees who are active in implementing innovations, ensure a reasonable innovative strategy, policy and current plans enabling use of personnel's innovation potential fully.

Assessment of probable personnel's attitudes to innovations underlies research into the degree of inertia of their behavior within innovations activities. It should be noted that not all employees in groups with obvious or potential activity can exercise real activity in implementing innovations. This is caused by both subjective - individual characteristics of each employee (e.g. an insufficient professional and educational level, low ability of creative thinking, lack of experience and skills in their professional sphere, etc.) and objective factors (e.g. lack of innovation policies and planning, the unfavourable climate in the team for production of innovations, inefficient management, etc.). So, the degree of inertia of personnel's behavior can be determined on the basis of objective and subjective reasons and the matrix of their probable attitudes to innovations.

We suggest analyzing the degree of personnel's behavior inertia when implementing innovations by the matrix method (Table 2).

Table 2. The matrix of assessment of personnel's behavior inertia when implementing innovations.

\begin{tabular}{|c|c|c|c|}
\hline $\begin{array}{r}\text { Degree of } \\
\text { activity }\left(K_{A}\right)\end{array}$ & \multicolumn{2}{|c|}{ Activity } & Inertia \\
\hline \multirow{2}{*}{ Acceptance } & \multirow{2}{*}{$\begin{array}{c}\text { Active } \\
\text { acceptance } \\
7 \leq K_{A} \leq 10 \\
7 \leq K_{P} \leq 10 \\
\end{array}$} & & \multirow{2}{*}{$\begin{array}{c}\text { Inertial } \\
\text { acceptance } \\
1 \leq K_{A} \leq 4 \\
7 \leq K_{P} \leq 10\end{array}$} \\
\hline & & \multirow{2}{*}{$\begin{array}{c}\text { Indifference: } \\
5 \leq K_{A} \leq 6 \\
5 \leq K_{P} \leq 6\end{array}$} & \\
\hline \multirow{2}{*}{ Resistance } & $\begin{array}{c}\text { Active } \\
\text { resistance }\end{array}$ & & \multirow{2}{*}{$\begin{array}{c}\text { Inertial } \\
\text { resistance } \\
1 \leq K_{A} \leq 4 \\
1 \leq K_{P} \leq 4\end{array}$} \\
\hline & $\begin{array}{c}7 \leq K_{A} \leq 10 \\
1 \leq K_{P} \leq 4\end{array}$ & & \\
\hline
\end{tabular}

Each quadrant of the matrix built on the integral coefficient enables describing a personnel group on the grounds of their behavior activity/inertia during implementation of innovations.

The integral coefficient of personnel's behavior activity/inertia is determined as follows:

$$
K_{I}=K_{A} K_{P}
$$


where $K_{A}$ is the coefficient describing the degree of personnel's activity when implementing innovations;

$K_{P}$ is the coefficient describing the degree of personnel's attitudes to innovations.

In terms of mathematics, we suggest determining the coefficients $K_{A}$ and $K_{P}$ as average values of the results of interviewing the personnel (a certain group of employees). The questionnaire must contain several questions for each group ("activity - inertia" and "acceptance - resistance") to provide accuracy of determining the four states of employee's behavior when implementing innovations.

So, we suggest the system of assessing employee's behavior when implementing innovations at the enterprise. For instance, results of the survey on the degree of personnel's activity in respect of innovation implementation enable determining the following behavioral states: "strong activity" - 9-10 points; "moderate activity" - 7-8 points; "strong inertia" - 12 points; "moderate inertia" - 3-4 points. In terms of personnel's attitudes to innovations, the following behavioral states can be singled out: "accept completely, will not resist" - 9-10 points, "accept partially, will not resist" - 7-8 points, "accept partially, will resist" - 34 points; "do not accept, will resist" - 1-2 points. The 5-6 point result indicates personnel's indifference towards innovations.

The quadrant "Active acceptance" describes a group of employees-innovators who have a strong desire to participate in innovative processes, produce, implement and use innovations.

The quadrant "Inertial acceptance" describes a group of employees who are fast in accepting innovations. They can participate in production, implementation and use of innovations after additional discussions, explanatory work, some consideration, under influence of other employees or being incentivized.

The quadrant "Inertial resistance" describes a group of employees with slow acceptance of innovations. They are reluctant to participate in innovative processes and skeptical of innovative changes. Their attitude to innovations is implicitly negative. However, strong or weak inertia of such employees, so called "drift", allows including them into innovation implementation under influence of majority of employees, through orders and directives of administration or through gradual persuasion.

The quadrant "Active resistance" describes a group of conservative employees who are strongly against any changes and their attitude to innovations is clearly negative. Employees of this kind are hard to be convinced or incentivized. If necessary and to save time, they can be forced into innovative processes. However, this group of employees hinders sustainable development of their enterprise. Considering the fact that all the employees of the enterprise participate in the innovative process to this or that degree, it is important to work with this group of conservative employees gradually and steadily to avoid resistance for their part to innovation implementation.

The quadrant "Indifference" describes a group of employees who have not found their position yet, know little about innovations at their enterprise or have not been engaged into innovative processes before and, therefore, do not have their own opinion of this issue. It is a sound idea for managers in the field of innovation activities to incentivize this group of personnel. Whether the employees will join innovators or remain conservative depends on the managers' work.

General attitude of the enterprise to innovations, the degree of personnel's resistance to their implementation, the rate of implementation depend on which group is the largest. Considering the above, it is important to investigate the measure of association between the factors: the degree of understanding the necessity of innovations and the degree of personnel's awareness; personnel's activity and their attitudes to innovations.

Calculation of the rank correlation coefficient is the easiest way of determining the measure of association between the factors. Spearman's rank correlation coefficient is the most common:

$$
\rho=1-6 \frac{\sum_{i=0}^{n} d_{j}^{2}}{n\left(n^{2}-1\right)}
$$

where $d_{j}$ is deviation of ranks of the factorial feature and the final result; $n$ is the number of ranks.

Let us assess the measure of association through the example of operating Ukrainian enterprises between:

a) the degree of personnel's awareness of innovation implementation at the enterprise and the degree of their recognition of the necessity of innovation implementation (Table 3);

b) personnel's attitudes to innovations and the degree of their activity (Table 4).

According to the data from Table 3, Spearman's rank correlation coefficient makes: $1-(6 * 4) /(6 *(36-1))=0.89$.

The rank correlation coefficient value indicates availability of the direct and rather significant association between the mentioned parameters of personnel's probable (expected) attitudes to innovation implementation.

The critical value of the rank correlation coefficient for $\alpha=0.05$ and $n=6$ will make $\rho_{0.95}(4)=0.89$ that is less than the actual value of $\rho$. Thus, essentiality of the association is proved with probability 0.95 .

According to the data from Table 4, Spearman's rank correlation coefficient makes: $1-(6 * 6) /(6 *(36-1))=0.83$.

The value of Spearman's rank correlation coefficient indicates availability of the direct and significant association between personnel's attitudes to innovations and the degree of their activity. The critical value of the rank correlation coefficient for $\alpha=0.05$ and $n=6$ will make $\rho_{0.95}(6)=0.83$ that equals the actual value of $\rho$. Thus, significance of the association is proved with probability 0.95 .

Summarizing the above, one can conclude that it is necessary to develop personnel's innovation potential to provide sustainable development of the enterprise. This process can be ensured through:

1) enhancement of personnel's attitudes to implementation of innovations;

2) optimization of personnel's behavior activity/inertia when implementing innovations. 
The performed analysis demonstrates that the first parameter depends on two interdependent factors - the degree of personnel's awareness of innovation activities and their recognition of the necessity of innovations. The second parameter depends on the degree of personnel activity and their attitudes to innovations.

Table 3. Intermediate calculations of determining the measure of association between the degree of personnel's awareness of innovation implementation at the enterprise and the degree of their recognition of the necessity of innovation implementation.

\begin{tabular}{|c|c|c|c|c|c|c|}
\hline Enterprise & $\begin{array}{c}\text { Average degree of } \\
\text { personnel's awareness }\left(K_{O}\right)\end{array}$ & $\begin{array}{c}\text { Average degree of recognition of } \\
\text { necessity of innovations }\left(K_{V}\right)\end{array}$ & $\begin{array}{c}\text { Rank of } \\
\text { indicator } K_{O} \\
\left(P_{O}\right)\end{array}$ & $\begin{array}{c}\text { Rank of } \\
\text { indicator } K_{V}\left(P_{V}\right)\end{array}$ & $\begin{array}{c}\text { Deviation of } \\
\text { ranks }\left(d_{j}\right)\end{array}$ & \begin{tabular}{c}
$d_{j}^{2}$ \\
\hline "A"
\end{tabular} \\
\hline "B" & 7.1 & 7.4 & 4 & 5 & 1 & 1 \\
\hline "C" & 7.7 & 7.5 & 6 & 6 & 0 & 0 \\
\hline "D" & 7.6 & 7.3 & 5 & 4 & -1 & 1 \\
\hline "E" & 6.6 & 7.1 & 3 & 2 & 1 & 1 \\
\hline "F" & 6.7 & 7.0 & 1 & 1 & -1 & 1 \\
\hline Total & 6.2 & 6.3 & & & 0 & 0 \\
\hline
\end{tabular}

Table 4. Intermediate calculations of determining the measure of association between personnel's attitudes to innovations and the degree of their activity.

\begin{tabular}{|c|c|c|c|c|c|c|}
\hline \multirow[t]{2}{*}{ Enterprise } & \multicolumn{2}{|c|}{$\begin{array}{l}\text { Degree of personnel's behavior activity/inertia when implementing innovations } \\
\text { by criterion }\end{array}$} & \multicolumn{2}{|c|}{$\begin{array}{l}\text { Rank of } \\
\text { indicator }\end{array}$} & \multirow{2}{*}{$\begin{array}{l}\text { Deviation of ranks } \\
\qquad\left(d_{j}\right)\end{array}$} & \multirow[t]{2}{*}{$d_{j}^{2}$} \\
\hline & "acceptance-resistance" $\left(K_{P}\right)$ & "activity-inertia" $\left(K_{A}\right)$ & $K_{P}\left(P_{P}\right)$ & $K_{A}\left(P_{A}\right)$ & & \\
\hline "A" & 7.2 & 5.9 & 5 & 4 & 1 & 1 \\
\hline "B" & 7.6 & 6.1 & 6 & 5 & -1 & 1 \\
\hline "C" & 7.0 & 5.5 & 3 & 3 & 0 & 0 \\
\hline “D” & 6.5 & 5.1 & 2 & 2 & 0 & 0 \\
\hline "E" & 7.4 & 6.5 & 4 & 6 & 2 & 4 \\
\hline "F" & 6.3 & 4.0 & 1 & 1 & 0 & 0 \\
\hline Total & averaged 7.0 & averaged 5.5 & & & & 6 \\
\hline
\end{tabular}

Personnel is known to be part of enterprise stakeholders, namely internal ones. In our opinion, part of security of stakeholders (including internal ones) is a component of enterprise economic security. Particularly, security of any group of stakeholders includes the part that depends on the enterprise performance (internal economic security of stakeholders) and the part that does not depend on it (external economic security of stakeholders). At that, general economic security of internal stakeholders and owners depend on this enterprise to the greater extent than security of other groups of stakeholders. Assessment of the economic security level of an enterprise $\left(L\left(E c S^{\prime}\right)\right)$ is integral and depends on the level of economic security of an enterprise as itself - without stakeholders $(L(E c S e))$, internal (dependent) economic security of stakeholders of the enterprise $(L(I E c S s))$ and external (independent) economic security of stakeholders $(L(E E c S s))$ :

$$
L E c S^{\prime}=f(L(E c S e) ; L(I E c S s) ; L(E E c S s)) .
$$

It is quite obvious that to provide its own economic security, the enterprise must at the same time provide security of economic interests of its stakeholders, including its personnel, by effecting certain payments. However, in some cases, the value of actual payments $(\mathrm{Pa})$ to serve the stakeholders' interests may be less than their compulsory payments $(P c)$. Then the concept of outstanding expenses $(E O)$ emerges:

$$
\begin{gathered}
E O=P c-P a, \\
E O \rightarrow \text { min. }
\end{gathered}
$$

In view of the above, we suggest assessing internal security of enterprise stakeholders, whose interests are served due to performance of their enterprise (dependent security of internal stakeholders as well as the enterprise owners) through the value of outstanding expenses. At that, the outstanding expenses may be both current unpaid spendings and the amount of outstanding investments. The latter are characterized by the depreciation value and percentage of payments. It should be noted that one part of payments for serving the stakeholders' economic interests decreases the value of earnings before tax and the other part is not considered. The first group of expenses comprises wages and other social payments to personnel; the other group is exemplified by dividends. The above mentioned enables enhanced classification of outstanding expenses of the enterprise (Fig. 1).

To assess the part of personnel's economic security which depends on the enterprise, we suggest determining the amount of outstanding expenses by each category (in the simplified form - employees and top-managers). Similarly, we suggest assessing the amount of outstanding expenses by other groups of stakeholders whose interests depend on the enterprise as well as owners of the enterprise. We consider the latter separately from other internal stakeholders as their economic interests may be connected with not only this enterprise but also with other enterprises. Besides, the dependent part of stakeholders' security includes environmental security maintenance of which is financed by enterprises not for the sake of profits but for satisfying the stakeholders' interests - first of all, the community within whose residence area the enterprise functions. 


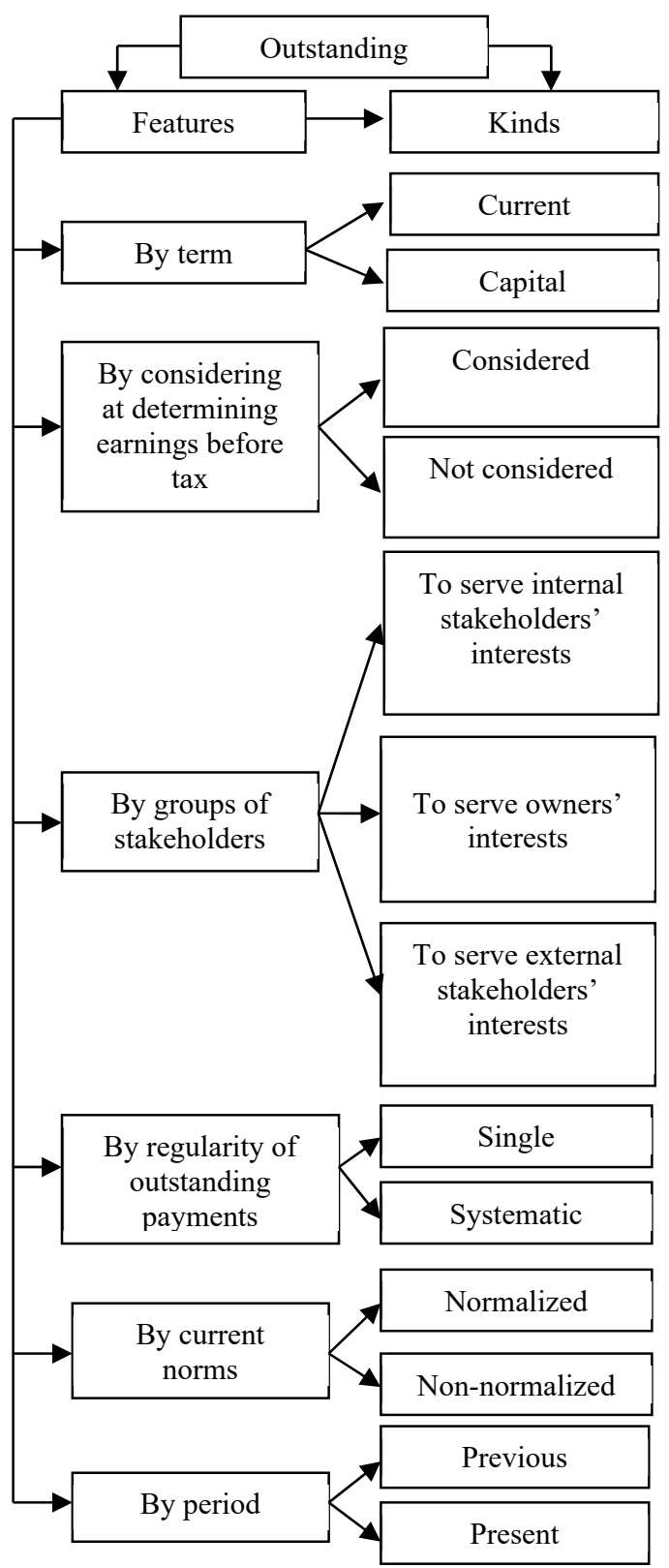

Fig. 1. Classification of outstanding expenses.

Thus, we suggest calculating the level of the dependent part of economic security of internal stakeholders whose interests are associated with the enterprise and of the enterprise owners and the area community $(L(I E c S s)$ according to the formula:

$$
L(I E C S S)=1-\frac{E O}{P a},
$$

where $E O$ is the amount of outstanding expenses, USD;

$\mathrm{Pa}$ is the actual amount of payments effected to serve economic interests of internal stakeholders, owners and the community, USD.

The obtained data should be compared with the suggested scale:

- at $L(I E c S s)<0$ - danger;

- at $0 \leq L(I E c S s)<0.25$ - the minimal level of the dependent part of internal stakeholders', owners' and the area community's security;
- at $0.25 \leq L(I E c S s)<0.5$ - the low level of the dependent part of internal stakeholders', owners' and the area community's security;

- at $0.5 \leq L(I E c S s)<0.75$ - the average level of the dependent part of internal stakeholders', owners' and the area community's security;

- at $0.75 \leq L(I E c S s) \leq 1.0$ - the high level of the dependent part of internal stakeholders', owners' and the area community's security.

Considering the approach suggested in [9], to assess the level of economic security of the enterprise, we propose determining the value of $E B T$ deficit instead of the operating income deficit. This value is the sum of the short-received earnings before tax which is required for the indicators of each type of economic security to equal the set values (characteristic, critical, reference, boundary, threshold, set, planned, recommended, desired ones). Economic security indicators reflect various aspects of financial-economic activities of the enterprise. For instance, probability of bankruptcy and income adequacy are indicators of the financial components of economic security; labor efficiency and workforce availability ratios are indicators of the personnel component.

We believe the indicator of deficit of earnings before tax $(E B T)$ to be relevant for assessment of the economic security level of the enterprise as from the analytical point of view it contains all the advantages as the net income but the results obtained on the basis of its calculation may be used for comparing similar data of enterprises with various taxation modes.

It should be noted that if the financial result of an enterprise's activity for the assessment period is losses (i.e. the actual value of $E B T(E B T a)$ is negative $(E B T a<0))$, the situation should be recognized dangerous. Therefore, further calculations of the economic security level are inexpedient.

It should be stressed that $E B T$ deficit $(\triangle E B T)$ is characterized by the positive value which is determined through equating actual values of corresponding indicators to their set values. In this case the following condition is fulfilled:

$$
\triangle E B T>0 .
$$

If the calculation results show excess $E B T$ value, i.e. $\triangle E B T<0$, the following condition is accepted for further calculations of the economic security level of the enterprise:

$$
\triangle E B T=0 .
$$

The smaller the values of the sums of outstanding expenses $(O E)$ and deficit of earnings before tax $(\triangle E B T)$ are, the higher economic security of an enterprise is.

Thus, considering the above, we suggest calculating the level of economic security of the enterprise $(L(E c S))$ by the formula:

$$
L\left(E c S^{\prime}\right)=1-\frac{\Delta E B T+E O}{E B T r},
$$

where $\triangle E B T$ is the value of deficit of $E B T$ which is required for the indicators of each type of economic 
security to reach the values set by enterprise management (or by other means), USD:

$$
\triangle E B T \rightarrow \min .
$$

$E O$ is the amount of outstanding expenses, USD;

$E B T r$ is the reference amount of the $E B T$ indicator, USD:

$$
E B T r=E B T a+\triangle E B T,
$$

where EBTa is the actual amount of the EBT indicator, USD.

To conclude about the level of economic security of an enterprise, it is reasonable to use the scale similar to the above mentioned: the higher the level of economic security of the enterprise is, the greater the value of the $\left(L\left(E c S^{\prime}\right)\right)$ is and the closer it is to 1 .

It should be noted that starting from 0.5 , the level of economic security of the enterprise corresponds to the average one, starting from 0.75 it corresponds to the high level. We believe that these are the most relevant values on achieving which the personnel's innovation activity can be directed at ensuring sustainable development of the enterprise. Here, the degree of personnel's innovation potential should be considered. If its values are low, development of the enterprise will be encumbered or fail even at the average level of economic security (Table 5).

Table 5. The matrix of determining the type of enterprise development on the basis of comparison of the degree of personnel's innovation activity/inertia and the level of its

\begin{tabular}{|c|c|c|c|}
\hline \multirow{2}{*}{\multicolumn{2}{|c|}{ Grading scale }} & \multicolumn{2}{|c|}{ Level of economic security of enterprise } \\
\hline & & High & Average \\
\hline 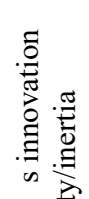 & 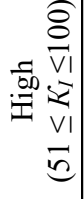 & $\begin{array}{c}\text { Innovative progressive } \\
\text { development }\end{array}$ & $\begin{array}{l}\text { Development based } \\
\text { on innovations }\end{array}$ \\
\hline 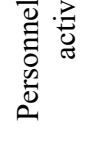 & 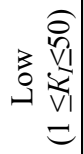 & $\begin{array}{l}\text { Development based on } \\
\text { economic security }\end{array}$ & No development \\
\hline
\end{tabular}
economic security.

Thus, comparison of the degree of personnel's innovation activity and the level of economic security of an enterprise enables determining not only the possibility of sustainable development but also its type.

\section{Conclusions}

The research conducted enables complementing the current concept of determinants of sustainable development with such components as personnel's innovation activity and economic security of an enterprise.

The suggested methodological principles of assessing economic security of an enterprise enable determining separately the dependent part of economic security of its internal stakeholders including its personnel, its owners and the area community. This approach is gaining topicality, as innovative activity of personnel who do not feel secure will not correspond to the level required to ensure sustainable development of the enterprise. The developed economic and statistic toolkit of assessing probable attitudes of the personnel to implementation of innovations enables considering the degrees recognizing the necessity of innovations and the personnel's awareness of innovation activities of the enterprise. Innovative-progressive development is only possible at simultaneous achievement of the high level of the innovation potential of the personnel and the high level of economic security while the low level of the innovation potential leads to lack of development at the moment of assessment even at the average level of economic security of the enterprise.

Thus, the approaches and the developed economic and statistic toolkit presented in the article are a new scientific solution to assessment of the degree of enterprise development depending on its economic security levels and innovation activity of the personnel.

\section{References}

1. S. Efymova, T. Grynko, Bulletin of Dnipropetrovsk University 5, 30-37 (2015)

2. A. Boychuk, Marketing and Management of Innovations 2, 129-143 (2016)

3. I. Nazarenko, Transport and industrial economics bulletin 37, 254-259 (2012)

4. O. Prudenko, B. Melnyk, Efficient economy 4 (2019). doi:10.32702/2307-2105-2019.4.46

5. T. Wihlman, M. Hoppe, U. Wihlman, H. Sandmark, Nordic journal of working life studies 4(2), 159-180 (2014)

6. Yu. Levchenko, Socio-Economic Research Bulletin 4, 208-215 (2012)

7. T. Grynko, T. Gviniashvili, Economic Annals-XXI 65(5-6), 80-83 (2017). doi:10.21003/ea.V165-17

8. M. Adamenko, Economic Annals-XXI 3(27), 49-59 (2014)

9. V. Potudanskaya, N. Borovskikh, E. Kipervar, Espacios 38(49), 9 (2017)

10. R. Skrynkovskyy, T. Protsiuk, L. Sytar, O. Shpak, Path of Science 4 (3), 4001-4007 (2018). doi:10.22178/pos.32-3

11. Ye. Hryn, T. Vlasenko, Internauka. Series: "Economic Sciences" 9 (2019). doi:10.25313/25202294-2019-9-5222

12. M. Samarah, B. Stark, J. Kindle, L. Payton, International Scholarly and Scientific Research \& Innovation 13(9), 1274-1281 (2019)

13. Cornell University, INSEAD, World Intellectual Property Organization, The Global Innovation Index 2017, https://www.globalinnovationindex.org/gii2017-report. Accessed 5 Mar 2020

14. Cornell University, INSEAD, World Intellectual Property Organization, The Global Innovation Index 
2018,

https://www.wipo.int/publications/en/details.jsp?id= 4330. Accessed 5 Mar 2020

15. Cornell University, INSEAD, World Intellectual Property Organization, Global Innovation Index 2019, https://www.globalinnovationindex.org/gii2019-report. Accessed 5 Mar 2020

16. V. Nusinov, O. Molodetska, K. Ponomarenko, Investments: practice and experience 23, 11-14 (2012)

17. M. Khvesyk, I. Bystryakov, H. Obykhod, Yu. Khvesyk, Economic Annals-XXI 170(3-4), 2226 (2018) 